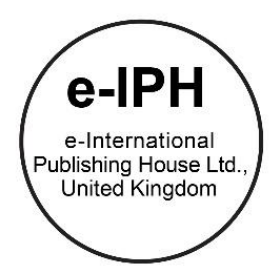

\title{
Berita Satu News Channel's Policy and Marketing Communication Process in Gaining Customer
}

\author{
Hadiono Afdjani, Julian Andretty \\ Universitas Budi Luhur, Jakarta, Indonesia \\ hadiono.afdjani@budiluhur.ac.id, andrettyjulian@gmail.com
}

\begin{abstract}
This research is related to Berita Satu News Channel's marketing communication activity based by the application of a redactional policy of a press company in the form of a television station in the paid network of cable television and satellite. Berita Satu News Channel's marketing communication activity utilizes the majority of Lippo Group network's force, which acted as the core company. These research theories are the organizational control theory and the promotional mix theory. Post-positivism is the paradigm that's used with its qualitative approach and a descriptive method to depict a real marketing communication process execution of Berita Satu News Channel.
\end{abstract}

Keywords: Policy, Redactional, Communication, Marketing, Television, News, Journalism, News

eISSN: 2398-4287 @ 2020. The Authors. Published for AMER ABRA cE-Bs by e-International Publishing House, Ltd., UK. This is an open access article under the CC BYNC-ND license (http://creativecommons.org/licenses/by-nc-nd/4.0/). Peer-review under responsibility of AMER (Association of Malaysian Environment-Behaviour Researchers), ABRA (Association of Behavioural Researchers on Asians) and cE-Bs (Centre for Environment-Behaviour Studies), Faculty of Architecture, Planning \& Surveying, Universiti Teknologi MARA, Malaysia.

DOI: https://doi.org/10.21834/ebpj.v5iSl1.2292

\subsection{Introduction}

Society needs a lot of information to develop intellectuality and collective knowledge to escalate human resources in every sector. Each issue that's discussed by mass media, especially television seems always to get the spotlight of society. The audio-visual advantages that are included in television assumed to be able to deliver information well that it's ready to acquire people's interest to rely upon it as their primary source of information. This phenomenon hits the television station business hard that it triggers competition between today's television stations. It was the base of why marketing communication concepts are needed in the world of broadcasting. To be able to get the public interested in watching their show programs, a television station has to be able to devise a practical marketing communication concept. Berita Satu News Channel necessitates its customer to subscribe to a particular cable television and satellite network to be able to enjoy their offered programs. In another side, Berita Satu News Channel only provides programs richly filled by the essence of valuable news for specific audience segmentation.

Marketing communication referring to promotional activity had some variety in its application that's often called a promotion mix. Promotional mix depicts creative ways that influence the consumer in their purchase of a product and service. The company could do various promotional campaign by using the combination of the promotional mix. The promotional mix is defined as a scrupulous guide of advertisement, personal selling, selling promotion, and the connection of society in the resort of achieving the promotional purpose of a company or organization (Tjiptono, 2002). Promotional mix theory used as an analytical knife in this research with the lieu of Berita Satu News Channel's reason being principally used some of form of activity categorized in the promotional mix in its effort of marketing communication establishment, mainly in its advertisement using some mass media brand and social media.

Berita Satu News Channel presents news quotes about various issues and recent happenings of its program's main theme in each of its program advertisement. In choosing the type and mass media brand and news material in its program's advertisement content Berita Satu certainly had various consideration mixed by its redaction crew and is still related to the redactional policy as the main foundation of a mass media company. Redactional policy influences that involve the integral component of the organization in this

eISSN: 2398-4287 ( 2020. The Authors. Published for AMER ABRA cE-Bs by e-International Publishing House, Ltd., UK. This is an open access article under the CC BYNC-ND license (http://creativecommons.org/licenses/by-nc-nd/4.0/). Peer-review under responsibility of AMER (Association of Malaysian Environment-Behaviour Researchers), ABRA (Association of Behavioural Researchers on Asians) and cE-Bs (Centre for Environment-Behaviour Studies), Faculty of Architecture, Planning \& Surveying, Universiti Teknologi MARA, Malaysia.

DOI: https://doi.org/10.21834/ebpj.v5iSI1.2292 
redaction is also the main reason for the utilization of organizational control theory as one of the analyzation instruments used in this research. Organizational control theory was proposed by Philip Tomkins and George Cheney, who's interested in general communication moulds control over the employee. Tompkins and Cheney introduce an approach that could be of use to explain organizational communication. Philip Tomkins and George Cheney propose a new and beneficial notion towards corporate communication through theory about regulatory supervision or control in a sociocultural culture. An example of sociocultural control focus towards an organization is about structure and form. An organization's character and personality often called organization culture, which consists of a variety of collective rules, norm, value or measure that could be used and accepted in an organization (Morissan, 2013). Based on all the things that have been elaborated before, the researcher is interested in observing even more thoroughly about the marketing communication process that's done by Berita Satu News Channel. With a guarded news value as its foundation in their fabrication process of advertisement as a marketing communication instrument, Berita Satu News Channel allegedly possessed a unique mixture originated from its redactional kitchen in their application of redactional policy combined with its marketing communication to escalate Berita Satu News Channel's popularity as a mass media brand higher that it helped in its attempt to gain more customer.

\subsection{Methodology}

This research exerts the post-positivism paradigm. Ontologically post-positivism characterized as critical realism which assumes that reality exists, and it corresponds to real things and nature's law nonetheless that the researcher can't rightly see it because of its relationship with his subjective personal assumptions. Epistemologically with modified dualist/objectivist in effect, the researcher's relation with the studied reality cannot be separated that it had to interact with the most minimum amount of subjectivity (Dewi, 2008). The author intended to reveal the phenomenon or reality also to analyze the systematic side of a marketing communication process to increase Berita Satu News Channel's consumer through direct observation and data collection. The data analyzation that's done is characterized as inductive based on the facts that have been found in the field, which then constructed as a hypothesis or theory. The qualitative approach is used in this research. It is expected to be able to generate a thorough brief about enunciation, writings. It conducts that's observable by an individual, group, society or a particular organization in certain context-setting which studied from a whole perspective. Utilized method of the research is qualitative descriptive to faithfully depict a variable, symptom, condition or a specific social phenomenon. In this case, to thoroughly and wholly analyze acquired data, an accurate perception of the discussed topic is necessary (Moleong, 2005). Data collection technique executed in this research is using primary data which formed as a thorough interview by asking questions to the informant, and secondary data which acquired from literature study, internet, courses notes and other data sources to complement analyzation support data and author's conclusion (Kriyantono, 2008).

\subsection{Results and Analysis}

Berita Satu News Channel applies specific rules in their marketing communication process to be cost-efficient and at the same time effectively reach a massive amount of audience which used to build its image as a reliable news television station that can be every source of reference for the people who needs information to perpetrate various social activity for collective importance. These things will eventually affect Berita Satu News Channel's promotional forms in their marketing communication process. Journalistic activity which is the main product of Berita Satu News Channel contains informational matrix which limits are regulated by the journalism ethic of conduct that demands every disseminated information to heed on it, including advertising which are of so many forms of its promotional activity. Advertisement is the most recognizable form of promotion because it potentially had the most extensive range.

There's two media strategy in promotional activity relating to the advertisement. They are; above the line promotional strategy which utilizes the characteristically indirect social media with a wide range of audience. The other one is below the line promotional strategy which conducts a characteristically direct and more personal in its marketing communication delivering effort. In this case, however, Berita Satu News Channel exerts a unique approach where both promotional strategies are fused with the help of media mix that is supported by digital technological forces and the internet so that both plans could run by each other. This above the line and below the line promotional strategy unification, usually called as through the line promotional strategy, which enable the utilization of promotional mix activity. The Promotional Division creates the advertisement of Berita Satu News Channel in News Magazine and Promo Department of Berita Satu News Channel. Led by a producer who's in charge to develop and develop the idea from a show and news program's promotion concept, also administer and coordinate every necessary production aspect of advertisement promo of Berita Satu News Channel. Berita Satu News Channel owns a variety of conduit as a medium to distribute their advertisement promo starting from television, daily paper, magazine, website and online media. The distribution of advertisement promo of Berita Satu News Channel through the website and online media is handled by the Website and Social media Department of Berita Satu News Channel.

The advertisement of various show program in Berita Satu News Channel always shows information snippets about the show's issue. The theme was chosen by Berita Satu News Channel redaction with news content whether in a hard news format or soft news which had actual and factual value. The creation of advertisement promo of Berita Satu News Channel's show program thoroughly done and needing a high aptitude on creativity. The instruments used in the advertisement of Berita Satu News Channel's show program referring to a container containing a specific issue and we the program's central theme. Some instruments referenced as a material in a news program's advertisements are; accurate prominent figure's soundbite (statement), news' visual (to faithfully depict an event), voice-over (narration), back sound (music), and graphic. Aside those main instruments used in the creation of Berita Satu News Channel's program's advertisement, there's a supporting instrument works as an attention grabber factor. The presenter could affect an aesthetic value of an ad of Berita Satu News Channel's program because a presenter is a figure considered as the hallmark of a show program. A presenter 
in a news program can be an icon that could give an impression and image to a show program-the foundation of a presenter figure in Berita Satu News Channel's show program's advertisement.

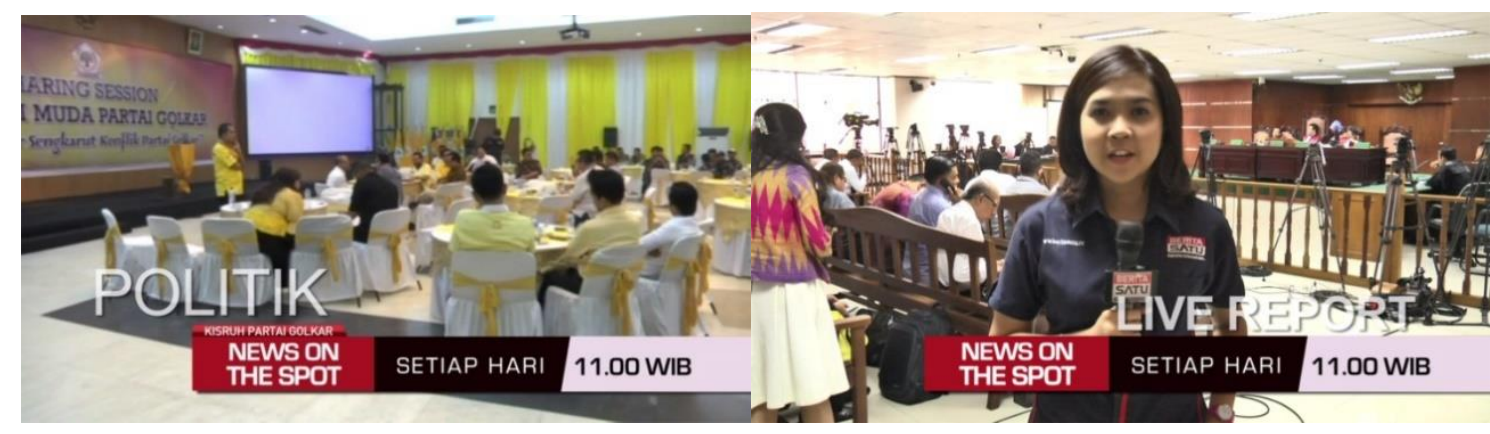

Fig. 1: Berita Satu News Channel's "NEWS ON THE SPOT" advertisement

They determine the use of a media in an advertisement's distribution, there's two essential consideration, which is; which media is going to be used and how often that media will be used (Morissan, 2013). Currently, there's some mass media variation that could be used to advertise. Operationally, however, there's some important factor in utilizing mass media variation, which is; primary purpose, product's characteristic, cost measurement, individual preference and others (Morissan, 2013). About this, Berita Satu News Channel as a media company seems to be strict in considering. The factor of media utilization as an instrument to disseminate their advertisement, namely exerting some mass media brand in Berita Satu Media Holdings Network as an integrated media core of Berita Satu News Channel.

Berita Satu Media Holdings harborsa lot of media brand as its integrated network members, some of which are; Berita Satu News Channel, Suara Pembaruan, Investor Daily, Jakarta Globe, Strait Times Indonesia, Singapore Press, Investor, Globe Asia, The Peak, Campus Asia, and Kemang Buzz. These mass media brands dispersed as a few types of mass media as an information distributor instrument such as paid cable television and satellite, daily newspaper, a weekly or monthly magazine and online media. This unified force of media is Berita Satu News Channel's main instrument in distributing their program's advertisements. Berita Satu News Channel spreads its ads across the variety of said brand media with a trading system so that there are no promotional costs needed to buy an ad spot. This endeavour able to appoint the marketing communication activity of Berita Satu News Channel to be more efficient, and more effective because of the marketing communication grasp is more comprehensive by the support of a variety of mass media with each of them having their audiences. It does not stop there; the marketing communication process of Berita Satu News Channel also penetrates the digital media realm through some social media that's been used by most people these days. The ever advanced feature of social media made a two-way communication between Berita Satu News Channel and its audience possible. Social media mixed the force of mass media with a broad approach that it could dwell its audience in one time with a piece of heterogenous information, with its ability of personal interaction supported by communication technology advancement it opens Berita Satu News Channel's opportunity to do a promotion mix activity by personal selling, sales promotion, public relation and word of mouth. Some social media sites used by Berita Satu News Channel are; Youtube, Instagram, Twitter ad Facebook, which all of them having like, share, comment feature and subscription and follow. The advertisement served by Berita Satu News Channel in social media most of the time takes a form of a banner or audio-visual snippets of news and show programs that could be played in a variety of digital communication devices.

In the realm of digital media and internet, Berita Satu News Channel also had an application that could be downloaded through an android and ios operated smartphone. Said app contains a variety of news offered in a written and video formats that could be enjoyed by smartphone users. It also have a live streaming feature that allows us to watch Berita Satu News Channel broadcasts through the app. However the broadcast quality of this app is not served in a Full High Definition (Full HD) format like the one broadcasted in its paid cable television and satellite network. This app fundamentally is a marketing communication instrument of Berita Satu News Channel in the form of a product demonstration, which in the app Berita Satu News Channel shows a variety of its journalistic works which also was the offered product of their paid television cable and satellite network. Berita Satu News Channel also inserts an app notification feature in its application to notify the app user about the most updated information served by Berita Satu News Channel in the app to support its news actuality so that it could immediately be disseminated to the public. From the broadcasting activity with its journalistic product til the marketing communication activity conducted by Berita Ssatu News Channel's redaction that's ever supporting and be supported by by the redactional policy it's visible how the organizational control is utilized. Organizational control shown by the existence of redactional policy that's acted as a guideline of every news coverage activity in Berita Satu News Channel redaction which also applicable to its marketing communication activity which are the information funnel to the public about Berita Satu News Channel's products. Refering to organizational control, this is a form of the validity of a birocratic control in Berita Satu News Channel redaction. Birocratic control constituted as a supervision that utilizes rules and formal procedures manifested by the existence of the redactional policy that demands every crew of the redaction to not stray from the previously agreed guidelines of Berita Satu News Channel which are the manifestation of its embraced attitude and value of its journalistic product creation, including advertisements as the front gate of Berita Satu News Channel redaction in serving an actual and factual news quotes. 
Berita Satu News Channel's advertisement creation process also depict how consertive control which was one of many controlling ways based on the organizational control theory. Consertive control is a supervision between employees using the interpersonal relations and team work came into effect in the process of advertisement promo creation of Berita Satu News Channel, whereas a tight coordination exist whether in one division of a department or between a lot of department with the purposely to attain the harmony between a journalistic products which are news with the created advertisement promo. The use of a simple control manifested in deciding the distribution channel of Berita Satu News Channel's marketing communication, which some of them are the decision process in picking some of a certain mass media brand in the integrated network of Berita Satu Media Holdings. This regulations applied to Berita Satu News Channel as a part of Berita Satu Media Holdings integrated network to exploit the integrated media by doing a promotional activity through a mass media brand that's also a member of the integrated media of Berita Satu Media Holdings. The advantage of the execution of promotional activity in the form of an advertisement in these integrated mass media brands is an example of a trade system promo of an advertisement in a various form without any costs from Berita Satu News Channel. This surely is not only advantageous to Berita Satu News Channel, but also the whole mass media brand that's integrated under Berita Satu Media Holdings which eventually could also widen their marketing communication range as well.

\subsection{Conclusion}

Berita Satu News Channel's redactional policy directly affects its marketing communication activity. This is caused by the content of the advertisement's instrument which was created by the redaction of Berita Satu News Channel contains news quotes and offered show programs which are the journalistic products of Berita Satu News Channel in its business practice. Berita Satu News Channel's redactional policy also affect its advertisement distribution instrument. As a part of a media integrated Berita Satu Medi Holdings, Berita Satu News Channel is responsible to do a news trade with the other integrated members, which also applied to in its marketing communication activity that require each of mass media brand integrated under Berita Satu Mass Media Holdings to do a promotional trade to sustain each marketing communication practices. Berita Satu News Channel's marketing communication imposed by promotion mix with through the line strategy which mostly exploits the online media and social media force to enables mass media forces fused with the personal interaction ability so that Berita Satu News Channel could do a two way communication with its audience which permits promotional mix in the form of personal selling, sales promotion, public relation and word of mouth to be done. Berta Satu News Channel utilizes promotion mix with media mix, whether a conventional mass media such as television, newspaper and magazine as well as modern mass media through the internet network which accessible from various digital devices such as computer and smartphone.

\section{Acknowledgments}

Author is ever thankful for Berita Satu News Channel for granting the permission for author to conduct this research. A bunch of thank you also for all the informants who have helped the author conducting this research by the form of interviews and data collection which used for the completion of this observation.

\section{References}

Dewi, L., \& Dwi R. (2008). Communication Theory: Understanding and Implementation. Tangerang: Renata Pratama Media.

Kriyantono, R. (2008). Practical Techniques Communication Research: Accompanied by Practical Examples of Media Research,Public Relations, Advertising, Organizational Communication, Marketing Communications. Jakarta: Kencana Prenada Media Group.

Moleong, J., L. (2005). Qualitative Research Methodology. Bandung: Remaja Rosdakarya.

Morissan (2013). Theory of Individual Communication to Mass. Jakarta: Kencana.

Tjiptono, F. (2002). Strategi Pemasaran. Yogyakarta: Andy Offset. 